\title{
Taking Responsibility for Educational Equity in Higher Education: A College Attainment Program for Underserved Young Women
}

\author{
Susan R. Warren \\ Capacity To Impact, Inc. \\ Nazanin Zargarpour \\ Capacity To Impact, Inc. \\ Min Hsuan Chen \\ Capacity To Impact, Inc.
}

\begin{abstract}
Research indicates that access to higher education is insufficient: a focus on student attainment through and beyond postsecondary education is needed (Carrell \& Sacerdote, 2017). This study assesses the impact of a college attainment program serving underrepresented female students. Mixed-methods combined quantitative measures of student outcomes with qualitative analysis of perceptions regarding program impact. Qualitative indicators were compared with the literature on key characteristics of college attainment programs (Webb et al, 2017). Findings indicate academic and social gains for participants and highlight associated program strategies. Results will inform the development, implementation, and evaluation of college attainment programs supporting all students.
\end{abstract}

Keywords: college access program, post-secondary attainment program, college persistence and completion, under-served youth and higher education

\section{PURPOSE}

A growing body of research and legislative policies across the globe have led to a movement dedicated to widening participation in higher education for all students, particularly those disadvantaged by social, cultural, economic, and geographic circumstances (European Access Network World Congress on Access to Post-secondary Education, 2015; Webb et al, 2017). Despite national educational and social initiatives to increase access, many within these groups in the United States remain marginalized (Page et al., 2019). Programs highlighted in the literature that have increased access and support for students to persist in and complete their higher education studies typically provide large sums of financial assistance (Scott-Clayton, 2015) and apply highly selective performance criteria in recruiting students (Goggin et al., 2016). By contrast, the current study draws from a comprehensive process and outcome evaluation of a program in its eighteenth year, Scripps College Academy (SCA), which serves a wide range of underrepresented young women. The program recruits from a plethora of urban high schools across three major counties in Southern California, with a moderate performance requirement of 3.0 grade point average (GPA). SCA provides a 
variety of support and resources throughout the students' high school and college years, however, it does not provide any financial aid. This study assesses the academic and social impact of the SCA program on its underrepresented female student participants and identifies effective strategies to advance higher education outcomes for underrepresented students.

\section{PERSPECTIVES}

\section{Educational Context}

The United States is becoming increasingly diverse, with a projection that by 2060 non-Hispanic whites will become a minority representing $44 \%$ of the population (Vespa et al., 2020). This trend is similarly reflected in college student demographics, indicating steady rises in enrollment for students of color, first generation students, and students from low-income households (U.S. Department of Education, National Center for Education Statistics, 2019). The growth may be attributed to educational and social initiatives to increase access to colleges and universities for students who are often disenfranchised by social, cultural, economic, and geographic circumstances. Yet, despite these efforts to increase access, many underrepresented students remain marginalized in college persistence and degree attainment (Page et al., 2019).

Data indicate that providing access to higher education is insufficient. It is not enough to provide financial assistance for diverse, underrepresented students (Carrell \& Sacerdote, 2017). Additional college knowledge and support are needed to successfully navigate college campus cultures, which are often very different from the lived experiences of marginalized low-income students and students of color and can, therefore, prevent a sense of belonging or thriving (Ash \& Schreiner, 2016). These disconnects, together with lack of college knowledge can lead to students dropping-out. National Student Clearinghouse Research Center data (2019) reveal that in the United States, $26 \%$ of post-secondary students are no longer enrolled after their first year. This figure is even higher for certain marginalized groups with $30 \%$ of Hispanic and $34 \%$ of Black students not returning for a second year of college.

Educators and policy-makers now focus on four key stages in students' higher education (HE) experience: (a) access to HE (gaining entrance to different types of HE institutions); persistence (the possibility of continuing in HE); attainment (being enabled to fulfill one's potential or achieving a degree); and progression (successfully transitioning with the program of study and afterwards to employment of continued study) (Webb et al., 2017). Research on key characteristics of college attainment programs that decrease student drop-out (Webb) and increase college persistence and degree completion for underrepresented students, points to developmental strategies that foster social-emotional learning, engagement, and belongingness (Cohen \& Garcia, 2014). Specific interventions can increase retention by up to $10 \%$. A variety of strategies, however, is necessary to address differing contexts (Thomas, 2012).

Based on the theoretical foundation above, the current study draws from a comprehensive process and outcome evaluation of the Scripps College Academy (SCA) program serving urban students in Los Angeles County. SCA offers free, year-round college-readiness support for an annual cohort of fifty low-income and first-generation female students of color. Program activities include a two-week comprehensive summer residency at Scripps College, year-round college-readiness support for students and their families, one-on-one consulting during participants' 11th and 12th grades in high school, and mentoring by current Scripps College students throughout high school, followed by the Successful Talented Resilient Impactful Vocal Empowered (STRIVE) segment of SCA which supports student persistence and completion while in college.

The summer program provides students college life experiences by including a two-week stay overnight on the Scripps College campus and participation in courses held by SCA program staff and Scripps faculty. Programming focuses on developing students' academic writing skills, research skills, social identity awareness, social emotional skills, college mindset, and college readiness and increases students' sense of belonging in college. Students later participate in college and financial knowledge workshops, ACT test preparation, field trips, and book clubs, and receive support with college applications. Beyond activities, students receive ongoing advice (e.g., on academics and college applications) from college mentors 
assigned to them. Families also receive services including help completing financial aid applications. Once the students are accepted and enrolled in college, the SCA program staff continuously connects with students on their college status, tracks students' persistence and completion rates, provides support including care packages, phone calls, resources, and other academic interventions as needed through the STRIVE college segment of the program. SCA also builds an academic and social community among each student cohort to engage peer support to and through college.

The strong supportive network provided by SCA broadens students' access to different types of colleges across the nation and strengthens students' capacity to sustain in higher education, resulting in positive outcomes, including high college enrollment, persistence, and 4-year completion. Positive college performance was initially identified in the process and outcome evaluation study of SCA conducted by the researchers. This includes a significantly higher college enrollment rate in private institutions and 4-year universities, and significantly higher college persistence with a 4-year completion rate of $70 \%$ (Zargarpour et al, 2020). The SCA Program findings are in contrast to the national average 4-year completion rate of 45.4\% in 2017 for all institutions (Causey et al, 2020) and the demographically matched counterparts average 4-year completion rate of $28.3 \%$ (Zargarpour et al., 2020).

The study of the SCA Program addresses gaps in the literature on successful college attainment programs that provide academic and social support other than financial aid and focuses on the following research questions (Page et al., 2019; Webb et al., 2017):

1. What do participants from underrepresented groups identify as the impact of the college attainment program on their academic and social success?

2. What strategies and activities do participants and staff identify as beneficial?

3. How do these strategies align with the literature (Tight, 2020; Webb et al, 2017)?

\section{METHODS AND DATA SOURCES}

This investigation was an 18-month case study utilizing mixed-methods (Creswell \& Cresswell, 2018). The study combined quantitative measurement of the impact of the program on participants using a quasiexperimental design, with qualitative analysis of the perceptions by participants and program staff of student growth and program strategies and activities.

\section{SCA Student Demographics}

The SCA program recruits a cohort of 50 high school students per year in the summer after their 10th grade year. Forty-six (46) of the 50 students beginning the program in the summer 2019 responded to the pre-survey, and their demographic information was collected. The SCA program staff also provided demographic information for the cohorts of 48 students who had just completed their senior year in high school in 2020 and 46 students who had just graduated from college in 2020. Participants, in this research study, within the different stages of the program will be referred to as high school graduates of 2022 (HS 2022), high school graduates of 2020 (HS 2020), and high school graduates of 2016 (HS 2016). Valid demographic data indicated that the majority of participants across the three cohorts in this study represented students of color $(\mathrm{N}=139,98 \%)$ and first generation to college students $(\mathrm{N}=136,87 \%)$.

According to the 2020 Federal Poverty Guidelines released by the U.S. Department of Housing and Urban Development (HUD), low-income families are defined as families whose incomes do not exceed $80 \%$ of the median family income for the region in which they live. Using the 2020 standards for Los Angeles County in California (U.S. Dept. of Housing, 2020), the researchers determined that ninety percent (90\%) of the SCA participants were estimated to come from low-income families across the three cohorts: $100 \%$ in the HS 2022 cohort, $91 \%$ in the HS 2020 cohort, and 97\% in the HS 2016 cohort.

\section{Quantitative Research Methods}

Surveys

Online pre- and post-surveys were designed in 2019 to gather data on: (a) student demographics, (b) summer program experience and perceived impact, and (c) desired student outcomes including critical 
thinking, social justice, academic writing skills, college knowledge, and college mindset using a five-point Likert scale and several open-ended questions. A total of 47 (94\%) of SCA participants in the HS 2022 cohort completed the pre-summer program survey and 49 (98\%) completed the post-summer program survey. Descriptive statistics were conducted to indicate the demographic information about the participants. Paired sample t tests were conducted by constructs to investigate student experience in the program, knowledge gained, and social-emotional growth on the desired outcomes.

A post high school online survey was designed to gather data on HS 2020 cohort students: (a) participants' overall program experience, (b) perceived impact, and (c) desired student outcomes. Participants rated various items using a five-point Likert scale and responded to several open-ended questions. A total of $43(86 \%)$ of the participants completed the survey. Descriptive statistics and content analysis were conducted to analyze the data from the participants.

\section{College Performance Data}

College data including college enrollment, college types, persistence, and 4-year completion were collected from the HS 2016 cohort. A quasi-experimental design was utilized to uncover the impact of the SCA program on these college outcomes. The researchers selected a dataset of over 1,500 high school graduates in 2016 from its own database as a comparison group. It contains college outcomes of a school district with a student population that is geographically and demographically similar to the SCA participants in the HS 2016 cohort. After removing both SCA participants and comparison group students who were missing key variables, 30 SCA participants out of 46 and 365 comparison students had data that were valid and used for the matching process. The researchers employed a Propensity Score Matching (PSM) approach with a nearest match method to match by gender, first generation to college, ethnicity, income, high school graduation, college acceptance, and college enrollment date. The purpose of this PSM approach was to control the baseline status of the comparison group students and minimize the selection bias and external factors that may affect the research findings (Loni Bordoloi, 2015; Perna \& Jones, 2013).

Sixty (60) comparison group students were matched with the 30 SCA participants, a 2:1 ratio, with consideration to optimize the largest possible sample size while maintaining the rigor and precision of the matches and minimizing potential matching bias (Austin, 2010). Because of the similarity of the students, there is a higher chance that the differences of the college outcomes between the two groups, if any, are related to the SCA program and its impact. Descriptive statistics on college enrollment and persistence were utilized for the SCA participants and Chi-Square significance tests were conducted to compare SCA participants and the matched comparison group on college types and 4-year completion.

\section{Qualitative Research Methods \\ Observations}

The researchers reviewed program related documents and observed one faculty and staff $(\mathrm{N}=16)$ writing course training facilitated by the faculty liaison, one staff $(\mathrm{N}=18)$ meeting during the semester, and a final program luncheon at which students $(\mathrm{N}=49)$ performed their favorite aspects of the program, in groups, as appreciation to the SCA and Scripps College staff and faculty. The observations of program elements and survey findings were used to inform the interview and focus group protocols for deeper inquiry into program strategies and outcomes.

\section{Interviews and Focus Groups}

A total of four focus group interviews were conducted with participants at various points in the program: (a) rising high school juniors as they completed their first SCA experience in the summer $(\mathrm{N}=$ $7)$, (b) recent high school graduates $(\mathrm{N}=4)$, (c) students in college and alumni $(\mathrm{N}=8)$, and (d) alumnae $(\mathrm{N}$ =2). Two faculty focus groups $(\mathrm{N}=3$ and $\mathrm{N}=3)$ and one focus group with college mentors $(\mathrm{N}=8)$. Individual interviews were conducted with the director, assistant director, faculty liaison, and two administrators overseeing the program. Informal meetings with the program administrators and faculty liaison also provided additional data about the program. The interviews and focus groups represent the perspective of SCA participants at various segments in the program and stakeholders in the various roles. 
Questions addressed SCA student experiences, observed growth or changes in desired student outcomes, perceived program elements contributing to persistence and success, and benefits or challenges of the program. Analysis of qualitative data employed triangulation and constant-comparison methodology (Corbin \& Strauss, 2015).

After collecting the open-ended responses from the summer and senior participant surveys and the transcripts of the 10 focus groups and interviews, the researchers grouped them into six data source categories: high school participant surveys, high school participant focus groups, college mentors, STRIVE and alumnae, faculty, and staff leaders and college administrators. Then the researchers participated in both an independent and collaborative process for interpreting different levels of emerging category themes (Creswell \& Creswell, 2018).

The first step in the process included the researchers reviewing and reflecting on the twelveindependent data sets in order to agree upon one listing of open-coding patterns for each data source. Then these open patterns were combined with open patterns from the same participant group. The researchers, in the second step of the coding process, continued their collaborative reviewing, reflecting, and re-confirming to interpret a more salient, second-level set of axial-coding themes (Creswell \& Creswell, 2018) for each of the six data source categories.

A striking result in the second step of analysis was the appearance of the eleven (11) axial themes, five related to program elements and six related to program outcomes, that emerged from the open-ended high school participant surveys and the focus groups and interviews, as shown in Table 1. Six program outcomes were identified as a result of the SCA Program: College knowledge, college mindset, critical literacy (critical thinking and social justice), academic and personal growth, enhanced self-confidence, and a ripple effect. The five program elements which participants and stakeholders acknowledged include relationship building, staff support, extra-curricular activities, family support, and emotional support.

TABLE 1

COMMON AXIAL THEMES OF THE SCA PROGRAM ELEMENTS AND OUTCOMES

\begin{tabular}{|c|c|}
\hline $\begin{array}{c}\text { Axial Themes } \\
\text { (Number of Data } \\
\text { Sources) }\end{array}$ & Open Themes \\
\hline \multicolumn{2}{|l|}{ Program Outcomes } \\
\hline $\begin{array}{l}\text { College Knowledge } \\
\text { (6) }\end{array}$ & $\begin{array}{l}\text { - } \text { Broadened horizons of college choices } \\
\text { - } \text { Gained information on college access and resources } \\
\text { - Received college admission knowledge } \\
\text { - Received financial aid knowledge } \\
\text { - } \text { Dispelled myths about college } \\
\text { - } \text { Learned what college is all about } \\
\text { - Experienced college campus in summer } \\
\text { - Prepared for ACT college entrance exam }\end{array}$ \\
\hline College Mindset (6) & $\begin{array}{l}\text { - } \quad \text { Felt prepared for college } \\
\text { - Understood college fit } \\
\text { - Understood the realities of college life } \\
\text { - Increased future self-expectations } \\
\text { - Opened minds about options for college } \\
\text { - } \quad \text { Developed a sense of belonging to college }\end{array}$ \\
\hline
\end{tabular}




\begin{tabular}{|c|c|}
\hline & $\begin{array}{l}\text { - } \quad \text { Developed an awareness of writing expectations } \\
\text { - Reduced anxiety about college going } \\
\text { - Built confidence about college going } \\
\text { - Demystified college application/admissions processes } \\
\text { - } \quad \text { Developed realistic expectations about college reach and fit } \\
\text { - Increased ability to navigate college systems }\end{array}$ \\
\hline Critical Literacy (5) & $\begin{array}{l}\text { - } \text { Gained analytic skills in writing } \\
\text { - } \text { Broadened vision } \\
\text { - } \text { Went out of comfort zone } \\
\text { - } \text { Increased ability to view issues from different perspectives } \\
\text { - } \text { Built critical thinking skills at political and a meta-level } \\
\text { - } \text { Encourned critical theory } \\
\text { - } \text { Exposed to systems of power and racism } \\
\text { - } \text { Developed social justice identity } \\
\text { - } \text { Challenged to think about social justice } \\
\text { - } \text { Gained social justice concepts } \\
\text { - Learned how to speak out against injustices } \\
\text { - Increased awareness about systems of power }\end{array}$ \\
\hline $\begin{array}{l}\text { Academic and } \\
\text { Personal Growth (5) }\end{array}$ & $\begin{array}{l}\text { - Increased writing skills and experience } \\
\text { - } \text { Gained research skills and experience } \\
\text { - Increased teamwork skills and experience } \\
\text { - Inpanded leadership skills and knowledge } \\
\text { - Expanded academic motivation } \\
\text { - } \text { Gained college experience (summer) } \\
\text { - Increased time management skills } \\
\text { - Gained an awareness of mental care } \\
\text { - Increased future self-expectations } \\
\text { - Enhanced self-advocacy } \\
\text { - Improved self-worth } \\
\text { - Raised expectations }\end{array}$ \\
\hline $\begin{array}{l}\text { Enhanced Self- } \\
\text { confidence (4) }\end{array}$ & 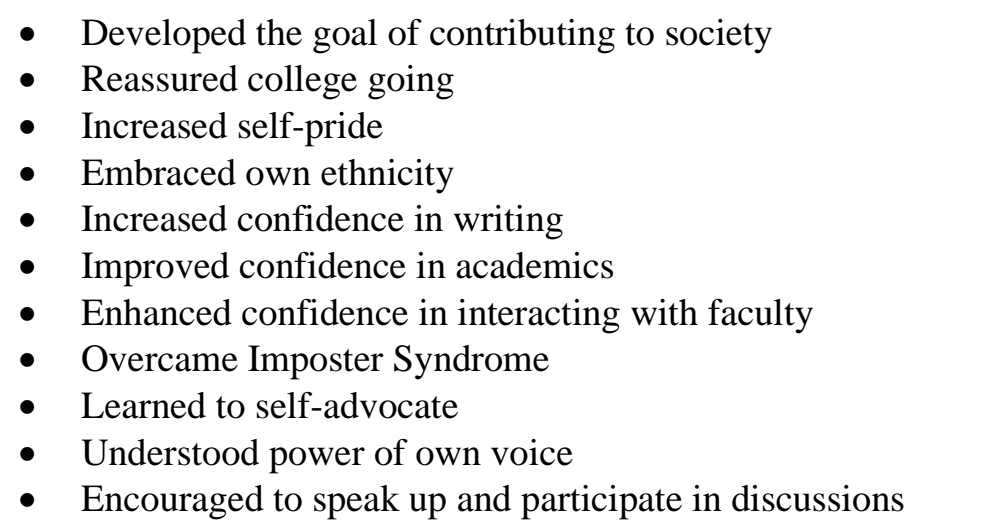 \\
\hline
\end{tabular}




\begin{tabular}{|c|c|}
\hline & $\begin{array}{l}\text { - } \text { Gained independence skills - doing things on own } \\
\text { - } \text { Became more comfortable talking to faculty } \\
\text { - Understood that SCA family will always support them }\end{array}$ \\
\hline $\begin{array}{l}\text { Creating a Ripple } \\
\text { Effect (3) }\end{array}$ & $\begin{array}{l}\text { - Influenced parents/families } \\
\text { - Impacted siblings of the students } \\
\text { - Influenced the community } \\
\text { - Motivated to help other students' with college jobs/career options } \\
\text { - Develop students' commitment of giving back }\end{array}$ \\
\hline \multicolumn{2}{|l|}{ Program Elements } \\
\hline $\begin{array}{l}\text { Relationships } \\
\text { Building (6) }\end{array}$ & $\begin{array}{l}\text { - } \text { Created new and strong bonds with Scripps faculty \& staff } \\
\text { - } \text { Made new friends with peers and supported each other in HS } \\
\text { - } \quad \text { Expilt academic community and network } \\
\text { in Mentor/Mentee (M \& M) program: from similar backgrounds } \\
\text { - Created a caring, family-like, friendly culture } \\
\text { - Maintained long-lasting, connections and support even as roles changed } \\
\text { - } \text { (to and through college, STRIVE) } \\
\text { - } \text { Provised on personal first } \\
\text { - Reduced fear of college going } \\
\text { - Shared faculty, staff and mentors' personal stories (role modeling) } \\
\text { - Provided one-on-one meetings between faculty and students } \\
\text { - Facilitated intentional team-building activities } \\
\text { - Connected with peers with similar background, hopes, dreams, and } \\
\text { goals }\end{array}$ \\
\hline Family Support (4) & $\begin{array}{l}\text { - } \text { Built trust between SCA and the families } \\
\text { - } \text { Developed personal relationships between SCA staff and the families } \\
\text { - Communicated in both English and Spanish } \\
\text { - } \text { Connected with the families about SCA goals } \\
\text { - Built a college going mindset } \\
\text { - } \text { Provided advising on the colleges' financial packages } \\
\text { - } \text { Held financial aid workshops and 1-on-1 help } \\
\text { - Implemented cultural sensitivity } \\
\text { - Understood families' situation } \\
\text { - Helped families to develop pride and a sense of relief }\end{array}$ \\
\hline Staff Support (6) & $\begin{array}{l}\text { - } \quad \text { Provided information about college life } \\
\text { - } \text { Demonstrated ongoing caring } \\
\text { - } \text { Expanded awareness of college options } \\
\text { - } \text { Provided continuous encouragement } \\
\text { - } \text { Encouraged self-advocacy } \\
\text { - Supported academic growth } \\
\text { - Provided personal and educational advising }\end{array}$ \\
\hline
\end{tabular}




\begin{tabular}{|c|c|}
\hline & $\begin{array}{l}\text { - } \text { Offered emotional support } \\
\text { - } \quad \text { Incorporated 1-on-1 discussions with faculty } \\
\text { - } \quad \text { Hired mentors from similar backgrounds }\end{array}$ \\
\hline $\begin{array}{l}\text { Extra-curricular } \\
\text { Activities (3) }\end{array}$ & $\begin{array}{l}\text { - Offered new opportunities (book clubs, plays, workshops) } \\
\text { - Included networking opportunities (internal and external) } \\
\text { - Strengthened bonds with staff and peers } \\
\text { - } \quad \text { Provided opportunities to engage with SCA students from mixed grade } \\
\text { levels } \\
\text { - Held book clubs } \\
\text { - } \text { Offered Field trips (plays) } \\
\text { - Provided STEAM workshops/labs/research }\end{array}$ \\
\hline $\begin{array}{l}\text { Emotional Support } \\
\text { (2) }\end{array}$ & $\begin{array}{l}\text { - } \text { Created a caring culture } \\
\text { - Supported faculty, staff, and students } \\
\text { - } \text { Stressed coping skills } \\
\text { - } \quad \text { Built independence of students } \\
\text { - } \quad \text { Sent college students care packages } \\
\text { - Provided connections to college resources/internships } \\
\text { - Personalized the support and resources } \\
\text { - } \quad \text { Conducted home visits when students were struggling }\end{array}$ \\
\hline
\end{tabular}

\section{RESULTS AND DISCUSSION}

Triangulated findings indicate that the overall impact of the program was positive for students. Qualitative findings provided deeper insights into program factors that students identified as contributing to their success in the surveys and focus groups. The following themes were identified among the program's salient outcomes and impacts: College Knowledge, College Mindset, Critical Literacy (Critical Thinking to Teach Social Justice), Academic and Personal Growth, Enhanced Self-confidence, and Creating a Ripple Effect. These outcomes were attributed to the following SCA program elements identified by participants and program stakeholders: Relationship Building, Family Support, Staff Support, Extra-curricular Activities, and Emotional Support. The SCA student outcomes and program elements will be presented for each research question along with corresponding findings from the literature.

Research Question 1: What do participants from underrepresented groups identify as the impact of the college attainment program on their academic and social success?

Findings on the academic success of HS 2016 cohort participants are based on student self-reported data. This included college acceptance, enrollment, and four-year completion. Using descriptive statistics, the data revealed that all (100\%) of the 30 SCA program participants in HS 2016 cohort were accepted to and enrolled in college in fall of 2016.

While more students, in both the SCA Program and the matched comparison group $(\mathrm{N}=60)$, enrolled in public institutions of higher education than private institutions, a significantly higher number of SCA students enrolled in private schools. Specifically, around two-thirds of the SCA students $(66.7 \%)$ enrolled in public universities and colleges and about one-third (33.3\%) enrolled in private schools whereas almost all of the comparison group students $(91.7 \%)$ attended public colleges or universities with only 5 students $(8.3 \%)$ enrolling in private schools. The significance level of the relationship between Group and College Type - Public or Private is high $(\mathrm{p}=.003)$. When comparing the college types in which students were 
enrolled in certificate programs, two-year colleges, and four-year universities, the difference between SCA and the comparison group is even stronger. Most SCA students (28 or 93.3\%) were enrolled in a 4-year university and only two (6.7\%) were enrolled in a 2-year college, while more comparison group students were enrolled in 2-year colleges (56.7\%) than 4-year universities $(41.7 \%)$, and one student $(1.7 \%)$ enrolled in a certificate program of less than 2 years. There is a highly, statistically significant association between Group and College Type -2 or 4 year $(\mathrm{p}<.001)$.

SCA participants also had significantly higher completion rates. As first-time students who began seeking a post-secondary degree at both two-year and four-year degree-granting institutions in the fall of $2016,70 \%$ of the SCA participants had completed an associate degree or a bachelor's degree at the same institution by 2020 - that is, within four years. This four-year completion rate is considerably higher than the national average 4-year completion rate of $45 \%$ in 2017 regardless of students' backgrounds and demographics (Causey, Ryu, \& Shapiro, 2020) and 28.3\% of the demographically matched comparison group students. A Pearson Chi-Square test of four-year college completion between SCA students and the comparison group shows high significance $(\mathrm{p}<.001)$.

The significance tests indicate that the positive results on college types and four-year completion may be attributed to participation in the SCA program and are not due to chance. Furthermore, many program participants on both surveys and in the focus groups attributed their positive outcomes to the program. Specific details are discussed in the subsequent sections below.

\section{College Knowledge}

An average of $87 \%$ of the SCA students are first generation in their families to attend college, therefore most reported having little to no assistance from home on understanding how to access institutions of higher education. Focus groups revealed that many of the SCA students also did not receive sufficient resources or information from their high schools about how to select, apply, and get accepted to the best college for them. Participants, however, mentioned that through the SCA summer experience on campus and workshops in their junior and senior years of high school they learned about: different types of colleges and universities, how to select institutions that best fit their talents and interests, and the application and financial aid processes. Special weekend sessions prepared them to take the ACT test and their college peer mentors and program staff helped them prepare their applications to college and understand a myriad of other necessary knowledge about institutions of higher education. They attributed this newfound knowledge about college to their ability to apply and be accepted into top tier colleges that were a perfect fit.

Among all survey results, the greatest gain acknowledged by participants was in college knowledge. Participants in the 2019 pre- and post-surveys showed a significant increase in knowing how to apply for financial aid ( $\mathrm{p}<.001)$, and most of the students in the post high school survey reported gaining knowledge on seeking financial resources (91\% agreed or strongly agreed, $N=43, M=4.26$ ). The students discussed, during the focus groups, how the meetings with Scripps College Financial Aid officers reduced their anxiety of paying for college. Research supports the importance of providing financial training to students about obtaining financial support for college access and managing their finances in college (Berumen et al., 2015). Burke and colleagues found that this knowledge is especially critical for underrepresented groups whose cultural values and dispositions may not align with the white, middle class notion of "the willingness to accept debt as an inevitable part of the pursuit of success (2013, p. 139)." Additional survey items including knowledge of college type, college admission, and college fit also all showed very strong significance ( $\mathrm{p}<$ .001). College fit was defined as selecting the college that best fits a participant's interests and situation.

Respondents in the 2019 pre- and post-surveys were also asked to rate their awareness of various college options before and after the summer program. Their awareness of the option of two-year community college increased by $11 \%$ (from $79 \%$ to $90 \%$ ). The transfer pathway option holds powerful potential, particularly for low-income students (Kilgore, Taylor, \& Pineda, 2020). While the greatest growth was in learning about the community college pathway, the pathways that most participants were aware of both pre- and post- summer programming were the four-year public (from 94\% to 98\%) and private (from 96\% to $100 \%$ ) universities. 
Another notable growth in college knowledge was in the percentage of program participants understanding the process of taking college level classes in high school which increased by $11 \%$ (from $85 \%$ to $96 \%$ ). This is a promising finding, as taking college level classes during high school (dual enrollment) has recently been linked to positive outcomes regarding accessing higher education. The research specifically shows that when students took either non-credit or for-credit college level courses in high school their confidence level and sense of belonging about going to college increased (Mehl et al., 2020). The workshops students experienced during the summer taught knowledge about this topic and showed a positive outcome in the data.

\section{College Mindset}

Another aim of the SCA Program, since its inception, has been to support the participants' growth in college mindset, the noncognitive factors such as perceived academic self-efficacy, motivation, and sense of belonging that have been found to predict academic performance and retention in college (Han et al., 2017). This was articulated by the students and staff throughout the surveys, focus groups, and interviews. There was a significant increase in college mindset on items in the 2019 pre-post survey where participants acknowledged that they see themselves being a college student someday $(\mathrm{p}=.031)$ and understand how to take college level classes in high school $(\mathrm{p}<.001)$. The high school participants described their growth in college mindset beginning with the on-campus summer experience that prepared them for living at a college. Throughout that experience and the following two years of high school, SCA faculty and staff continually helped them see themselves as successful and competent college students. Building relationships, confidence, and a family network provided them with the social and emotional foundation needed for going away to college. Participating in college-like activities on and off the Scripps campus throughout the two years also aided them in the preparation for college so that they could visualize what was to come. The result was that students raised their expectations about going to college, gained a sense of belonging to a network that supported their college journey, and felt prepared for college. The STRIVE college participants and alumnae echoed these comments, stressing the impact of the summer experience on a college campus as a significant part of their growth.

"During the summer experience on campus I developed independence and preparation to do things on my own. I realized I could go to a school and not know anyone." (participant)

"Through the college writing experience they [SCA students] change their mindset about their potential to attend college. They become comfortable talking to faculty and break down their initial anxieties. Much of this takes place outside of the classroom." (SCA Faculty)

Research on interventions to improve college student success have found that noncognitive factors such as mindset can be as critical as, or even more essential than, cognitive skills in determining academic outcomes. Academic mindset is positively associated with learning persistence, better academic behavior, and improved performance in school. Specifically, studies show that self-efficacy is closely associated with academic performance and belonging is closely associated with retention (Han et al., 2017). Castleman, Page, and Schooley (2014) found that two to three hours of summer counseling increased college enrollment (among college bound high school graduates) by 5 percentage points.

\section{Critical Literacy}

All student groups emphasized that the program has a focus on building critical thinking skills, particularly the ability to think critically about social justice issues. Participants spoke about the summer readings and research projects around social justice as well as the many planned discussions. They appreciated being challenged to think about social justice and be analytic about their writing. As most participants were women of color who were from low-income and first generation to attend college families, the SCA curriculum and discussions included exposure to injustices they might experience in higher 
education and greater society. This not only included understanding how they may be victims of injustices but also strategies for overcoming them. Additionally, the students learned the importance of speaking out against injustices and that their voices mattered. These opportunities continued during high school in the workshops and field trips that often reflected social justice themes.

"We had a workshop after a film on intersectionality with a dynamic discussion facilitated by our peer mentors. They let us know it's OK to stand out and speak out against injustices." (STRIVE college participant or alumna)

"It [SCA] creates an environment for thinking critically and encourages self-confidence. We feel open to express ourselves and be open to others' opinions." (STRIVE college participant or alumna)

While qualitative data reveal student learnings during the program in critical literacy, quantitative data from the 2019 pre- and post-surveys measuring their growth in critical thinking $(\mathrm{p}=.027)$ and social justice $(\mathrm{p}=.001)$ skills also show significant increases.

Educators, particularly critical theorists, have highlighted the importance of providing youth with critical literacy for the past five decades (Apple, 2012; Freire, 1970; Giroux, 1996). Critical literacy was born out of critical theory, an approach that emphasizes reflective assessment and critique of culture and society in order to reveal and challenge power structures. It is a way of being, knowing, and acting in the world that can expand youth's understanding of hegemony and its effects on marginalized groups (Apple, 2012). The theoretical framework underpinning critical literacy pedagogy encompasses two areas: the importance of critical reading and writing in constituting and reconstituting the self, and critical writing that is not just about coming to a critical understanding of the world but plays an explicit and self-referential role in changing the world (Morrell, 2015).

\section{Academic and Personal Growth}

Evidence supports the understanding that Social Emotional Learning (SEL) skills can mediate and predict key college outcomes such as college enrollment, persistence, and completion, especially for firstgeneration college students of color (Dymnicki et al., 2013; Latino, et. al., 2018; Porchea et. al., 2010). Additionally, research reveals that academic skills, study skills, and time management skills are critical for college readiness among first-generation college students, yet these needs are rarely met during high school (Reid \& Moore, 2008). Many college access programs designed to support first-generation, low-income students address topics such as financial aid, college admissions, personal and social growth including SEL competencies, and academic enrichment (Harvill et. al., 2012). Few, however, prepare the students for the academic rigor of college (Webb, 2017).

SCA participants acknowledged both academic and personal growth throughout the qualitative data. Academic growth was noted in their increased abilities in college-level writing and research as well as their ability to discuss literature with complex social justice themes. Personal growth was particularly identified in the areas of time management, mental care, self-advocacy, motivation, and self-worth.

Most of the items on the 2019 pre- and post-surveys related to growth in academic writing show statistically significant increases. These include their confidence level $(\mathrm{p}=.004)$, awareness of the thought process $(\mathrm{p}=.042)$, awareness of the strengths and weaknesses in writing $(\mathrm{p}=.005)$, ability to provide scientific evidence in writing $(\mathrm{p}=.012)$ and ability to analyze information $(\mathrm{p}=.001)$. The high school participants identified several specific areas on the open-ended survey responses in which they experienced "life changing" growth including writing skills, research skills, problem-solving, teamwork, and leadership. The students also acknowledged an increase in academic motivation as they grew in their academic abilities and ability to access college. They attributed this growth to many aspects of SCA: the summer program

experience, high expectations, and teamwork. The college mentors, STRIVE participants and alumnae also shared examples of growth in the same areas in their focus groups. 
"I vividly remember sitting with the writing professor in the courtyard. He provided feedback. I had never had a teacher say, 'Here's what's good and here's where you could improve." (STRIVE participant or alumna)

"The professors took my ideas and showed me how to make them better. They allowed us to keep the power of our own voices." (participant)

\section{Enhanced Self-Confidence}

All participant groups expressed that the program has an emphasis on building self-confidence. Beginning with the personal feedback and encouragement from faculty on students' writing, to building their speaking skills with practice college admissions interviews, to being shown the possibility of a broader and higher vision for their futures, the SCA Program increased the self-confidence of its participants academically, socially, and emotionally. They attributed being proud of themselves, embracing their ethnicity, setting high goals, and being able to speak-up about injustices in society to the many activities and the structure of the SCA Program.

"I went to an all-Black high school. Participating in SCA helped me understand I'm a firstgeneration student who can shine and speak-up!” (participant)

"SCA helped us gain confidence. I had imposter syndrome but SCA made it less." (STRIVE college participant or alumna)

Writing was the only academic area in the quantitative data that showed a significant increase in students' confidence levels $(\mathrm{p}=.004)$ from the summer pre- to post-survey. The summer program's focus on writing may be why this area had statistically significant results as mentioned in the Academic and Personal Growth section. Similarly, the short span of the Summer Residential Program may be why the other academic areas were not statistically significant.

The impact of students' psychological states of mind on their achievement has been increasingly studied over the past decade. For example, studies have found that many female students experience imposter syndrome, a phenomenon in which they do not believe they are bright or worthy of attending outstanding institutions of higher education, despite their excellent academic accomplishments (Edwards, 2019). Students who are typically underserved in higher education struggle with finding their place in privileged academic environments. Jury and colleagues (2017) explored the experiences of students from low-income backgrounds who were in university contexts and found that these students face considerable psychological barriers in comparison with their more affluent peers, including negative self-perception, emotional distress, and identity management issues. Parkman (2016) in a review of imposter syndrome in higher education, discovered that imposter syndrome scores are higher for minority student populations than majority student populations. Several studies also reveal that first-generation students experience imposter phenomenon more often and at higher levels than their non-first-generation peers (Martinez et al., 2009; Peteet et.al, 2015; \& Terenzini et al.,1996). Finally and of most importance, educational researchers have shown that even small social-psychological interventions in students' negative thought patterns and beliefs can result in increased self-confidence and self-efficacy, and positively impact academic attainment (Cohen \& Garcia, 2014; Yeager \& Walton, 2011).

\section{Creating a Ripple Effect}

An overarching theme of the focus groups with the high school participants, college mentors, STRIVE participants, and alumnae was about the impact of SCA beyond the direct benefits to participants. These program participants described the impact of SCA as a ripple. As they grew in their college knowledge and mindset, they took the learnings back home to share with their families, communities, and greater society. One alumna mentioned that through her success in the program, her younger sister became interested in college and went on to also be an SCA student who is currently participating in STRIVE. Others shared 
stories that evidenced the broader impact of their learnings from SCA in their interactions with community members.

Perhaps one of the most impressive findings during this evaluation supports the idea of creating a positive, lasting change in society, one of the intended impacts of the SCA program. When asked about their work experience during or after college, four of the six STRIVE college participants and all four alumnae participating in the two focus groups indicated that they work in an office or organization that supports marginalized students. They work in multicultural, cross-cultural, and diversity/equity/inclusion (DEI) centers at their colleges and universities, mentor high school students, conduct DEI research and edit a magazine on the topic, direct a college access program, and serve as college admissions officers who also support the SCA admissions process. These women are changing society by providing support to other students, building on the support they received from SCA themselves.

"This is an organization you can learn from and bring it back to your own community. They also check up on you and give support. There is a lot of support built in the system." (STRIVE college participant or alumna)

Findings from the quantitative responses on 2019 post-surveys as well as the 2020 post-high school survey support this notion of the ripple effect, demonstrating that students actively recommend the program to others. Most (96\%) of SCA participants on the 2019 post-survey agreed or strongly agreed that they would recommend the program to students interested in attending college, and most $(93 \%)$ of the SCA participants in the post-high school survey rated 10 out of 10 that they would recommend the program to other high school students.

Despite standard-economic models suggesting that people are primarily motivated by self-interest, a large body of research conducted by experimental economists and psychologists during the last decades reveals that a considerable percentage of people are strongly concerned about the well-being of others, fairness, and reciprocity (Halali et.at., 2016). Social science researchers use the term upstream reciprocity to describe a pay-it-forward style distribution of an unearned benefit to a third party after one has received a benefit from another benefactor. It is an expression of gratitude when an individual is motivated to extend generosity to a third party after receiving a benefit from someone (McCullogh et. al., 2008). Foundations and institutions of higher education have developed programs for students entering college that include or are built on the concept of upstream reciprocity (Boat et al., 2020). The Future Citizens Foundation (FCF), for example, created the Pay It Forward Scholarship and Mentoring Program that provides financial support and mentoring by a community leader to local first-generation college students. The recipients then "pay it forward" by mentoring younger FCF participants creating a cycle of local college students who are contributing to the community even as they study (Future Citizens Foundation).

\section{Research Question 2: What Strategies and Activities Do Participants and Staff Identify as Beneficial?}

Findings of academic and social gains for participants in the program are connected to specific program strategies and components. They are also aligned with key characteristics of college success programs in the literature (Tight, 2020; Webb et. al., 2017). The participant survey ratings, open-ended responses on the surveys, along with the many focus groups and interviews with SCA participants, alumnae, and stakeholders, provided rich data about the most effective activities and impactful aspects of the program. Focus groups with summer, high school, and STRIVE (SCA college level) participants; alumnae; and college mentors (half had been SCA participants) told the story of SCA from the participants' perspectives at different stages in the program and its impact on their lives. Faculty, staff leaders, and program administrators also shared valuable insights on elements of the program they perceived to have impacted the participants. Coding and analyzing the data, the evaluation team found that many common themes emerged across the focus groups and interviews with the participant groups and stakeholders. These themes are further supported by the quantitative findings. 


\section{Relationship Building}

Program participants overwhelmingly acknowledged the importance of relationships in SCA. These relationships began in the summer with peers, facilitators, residence advisors, faculty, and staff; continued throughout the program; and, for many, continued in their adult lives. The relationships are built upon opportunities to bond and form networks. The caring adults in the program create a family-like culture that is deepened with individualized attention throughout the various segments.

"At first I was nervous and intimidated by my peers in the summer. Then I realized my peers were part of a network, a community. I got to know them and still connect with them through social media." (STRIVE college participant or alumna)

"I was a participant...I get choked up talking about it...There's literally no program like this. The first day Robert [program director] said, 'SCA is going to be like a family.' It happened in those first two weeks. On our final day, all 50 girls cried seeing people who they didn't know two weeks before. Robert is the center of all of this. He's the face." (college mentor)

The participants from all segments of the SCA Program and alumnae explained how relationships with various stakeholders and peers positively impacted their lives in and after the program. They also identified many intentional ways these bonds were formed through program activities and supportive gestures by the stakeholders. In the post high school survey, 40 (98\%) out of the 41 respondents agreed or strongly agreed that SCA had provided them with an academic family and support system $(M=4.63)$. There was a particular expression of gratitude, however, about their relationships with the SCA staff leaders - the director and assistant director. The students admired the accessibility of SCA staff when needed $(98 \%, \mathrm{~N}=41, \mathrm{M}=$ 4.76), and that they still received regular communications from the staff after the summer program (83\%, $\mathrm{N}=41, \mathrm{M}=4.37$ ). They also discussed in the focus groups the incredible commitment of the current director and how they got to know and admire him through his personal story that was shared during the summer and visible actions reflecting care. Some of the mentors indicated that as participants who are at the Claremont Colleges [Scripps is a part of this consortium], they know that they can still visit the SCA office at any time and that the staff leaders will be there to support them. The STRIVE participants also mentioned that, through the relationships they had with the staff leaders, they feel that they can contact them for resources or help with anything. Finally, even the alumnae shared that they still maintain a strong relationship with the former SCA director who is a lifelong mentor as well as their SCA peers via social media.

The stakeholders' responses mirrored those of the participants adding the opportunities to build participant/faculty relationships with the one-on-one writing sessions in the summer and continuous mentoring from all adults in the program. Faculty and college mentors shared their own stories to connect with the participants. Additionally, the college mentors served as role models with backgrounds, hopes, dreams, and goals similar to those of the participants.

"The impactful part of the program is being around other students from similar backgrounds with the same hopes, dreams, and goals; being on a first name basis with professors who care; and having mentors they look up to...to guide them and tell their stories. All of these things build the story of who they are." (staff leader or administrator)

"SCA brings students together in a community of educators, facilitators, and participants. They see that everyone has something to contribute." (faculty)

The findings from this theme are substantiated in an abundance of literature. Research highlights the importance of supporting students with a myriad of relationships and networks throughout the stages of college: access, persistence or retention, attainment, and progression (Boat, 2020; Tight, 2020; Webb, 
2017). Studies substantiate the need to provide relationships that are both short term to give immediate help with the student's current needs as well as others that the student knows will be long-lasting. These relationships can even be mapped to assess each students' current connections and support (Boat, 2020). Ongoing support through staff and faculty relationships is critical in helping students overcome challenges in getting to and through college including dealing with new environments or cultural spaces, emotional stress, finances, and new academic expectations (Page, et. al., 2019).

\section{Support for Families}

The high school participants and college mentors recognized and appreciated the support that SCA provided both to them and to their families. SCA begins its support to families by building relationships with them in the summer and establishing patterns of trust. Communication is always in both English and Spanish (the primary language of many of the SCA families) to encourage participation and model respect. Students in the post high school survey recognized that through working with SCA staff, their families gained knowledge regarding college admissions and the college experience (84\% agreed or strongly agreed, $\mathrm{N}=43, \mathrm{M}=4.19$ ). One important area in which the program provided resources for the families was in understanding financial aid. SCA held workshops for the participants and their families and arranged for one-on-one support from Scripps College Financial Aid officers when the participants received their financial aid packages. The staff also helped prepare parents for the participants leaving for college and encouraged a college-going mindset. The post high school survey found that the families had become more supportive of their children going to college ( $74 \%$ agreed or strongly agreed, $\mathrm{N}=43, \mathrm{M}=4.16)$ after engaging with SCA staff.

The stakeholders shared that the support to families was an important aspect of the program. They provided this support through communicating about the SCA goals, hosting parent days, being culturally sensitive and understanding the families' unique situations, building a personal relationship with the families, and communicating in English and Spanish. Through these communication efforts, the SCA staff involved parents in the program and was able to build trusting relationships.

Involving students' families or "parent involvement" is one of the five common components of college access programs identified by Harvill and colleagues (2012), yet there is little in the current research on the topic. A seminal meta-analysis of hundreds of college access programs found only 14 that had independent evaluations that measured program impact on outcomes. Only three of the 14 incorporated Support for Families: Gear-up, Upward Bound, and ACE Plus (Harvill et. al., 2012). Other researchers found family support to be integral in motivating students' applications to college (Bernhardt, 2013; Gonzalez, 2013). Furthermore, a survey of access programs in Virginia showed that $27 \%$ listed parents as a major influence and 53\% listed them as a secondary influence (Webb, 2017). The findings of the SCA Program add to the literature in an area that is overall lacking.

\section{A Supportive Staff}

Related to relationships, the program participants in all data categories shared the many ways in which mentors, facilitators, RAs, staff, faculty, and their SCA peers support them throughout their time in the program and after college. The support is provided in academics, from the summer writing class to connecting STRIVE college participants to resources on their college campus. Emotional support is also provided in a multitude of forms from college advising to care with personal or financial challenges. Even the mentors continue to get support from the SCA staff and faculty while they are in college at Scripps. The participants mentioned that they stay connected through social media and continue to receive support from their peers and the stakeholders in SCA.

"I didn't know, really, anything about college and I probably would have made some bad choices about college, had I not gotten into this program. It's extremely reassuring that I'm not doing this by myself and now I have people who I know care about me to fall back on and to guide me every step of the way." (participant) 
"SCA has been one of the best experiences of my life. Not only do I get to leave the program knowing I made lasting friendships while gaining knowledge, but I get to stay in this program for 6 years. It is incredible how much SCA is impacting my life..." (participant)

The stakeholders elaborated about the value of the college mentors as a support for participants. The mentors are often SCA alumnae and/or come from the same high school as their mentees. They are selected for their ability to relate to the participants and form long-lasting, caring relationships. Faculty support, beginning in the summer and continuing throughout with workshops, presentations, and personal advising, is also key for the participants. Faculty are culturally, racially, and ethnically diverse and teach from their various backgrounds or disciplines. They provide social-emotional support for participants and help them build self-confidence in and out of the classroom.

"We actually care and they appreciate it." (staff leader or administrator)

The theme of A Supportive Staff aligns with the literature highlighting the importance of college access and attainment programs building students' social capital through support. Research shows that when program staff provide academic and social-emotional support as an intervention (Boat et. al., 2020), access and persistence increase. Successful programs that target support for Latinx students focus on culturally responsive strategies (Gonzalez, 2013) including peer mentoring to reduce cultural barriers (AmaroJimenez \& Hungerford-Kresser, 2013).

\section{Extra-Curricular Activities}

This theme was highlighted by high school participants and college mentors. While the participants valued the academic and college knowledge and mindset components of the program, they also appreciated the impact of the extra-curricular activities. Integrated into the summer program and provided on Saturdays during the school year, these experiences strengthened their bonds with staff and peers, provided them with new opportunities, and helped build networks of support that went beyond and outside of SCA. These activities included book clubs, workshops, field trips to plays, college visitation trips with presentations by participant alumnae, and opportunities to conduct Science, Technology, Engineering, Arts, and Math (STEAM) research with faculty. The participants shared that the activities consisted of participants from mixed grade levels, allowing them to meet new participants and expand their networks.

"I enjoyed going to campus for non-academic things like the book club and museum trips. It was a time for all SCA - mixed grade levels - to interact. I had never done a book club and I enjoyed it. They should have more." (high school participant)

"The non-academic activities were important as they helped students get out of the classroom to have fun and expose them to new things. I saw my first real play at the Pasadena Playhouse with SCA.” (college mentor)

While faculty did not elaborate on this theme, one faculty member shared, "Some activities may seem trivial, like the talent show or soccer, but they are building community outside of the class and seeing faculty as people." This theme, identified as social enrichment by Harvill and colleagues (2012), is one of the five common components of college access intervention programs. Researchers acknowledge, however, that programs vary greatly in this area with some providing summer only enrichment field trips and others building students' social capital throughout high school (Webb, 2017).

\section{Emotional Support}

High school participants on their open-ended survey responses and the STRIVE and alumnae focus group participants expressed the value of the emotional support they received from SCA. The high school 
group mentioned the care and support provided by the program. They shared that through SCA they learned coping skills, self-reliance, and independence. The STRIVE college participants and alumnae also highlighted the importance of ongoing communication from the program staff, even through college, as well as the feelings of appreciation they had for the care packages they received from SCA staff. One STRIVE participant said that her care package arrived at a "most needed time" when she was having family challenges. This group related that the personalized support they received from SCA staff via texts, emails, and phone calls often connected them to important and valuable resources at their own college, such as internships.

The impact of a student's psychological state on his or her achievement has been of increasing interest to researchers over the past decade. Studies indicate that interventions that target students' attitudes, assumptions, feelings, or beliefs and attempt to disrupt those that may negatively affect academic achievement are critical to student success (Webb, 2017). Attention to students' social-emotional learning is seen in access and persistence programs that include counseling, address cultural differences that may affect students' self-perceptions (e.g., imposter syndrome), and provide structural systems of support in this area from staff (Ramsey \& Brown, 2018; Stevenson, 2012).

\section{DISCUSSION}

There is a critical need for research on effective strategies to support low-income students to not only enter but successfully complete postsecondary education. Intervention programs that focus on a single dimension of student support such as financial aid or college admission guidance generally do not yield significant success rates. A more comprehensive approach to supporting access, retention, attainment, and progression in higher education, such as the SCA Program, can yield significant positive impacts (Page et al., 2019).

This investigation highlights elements of the SCA Program that contribute to its effectiveness and impact on the participants' growth in several areas, particularly their ability to select, access, and persist in colleges and universities that are selective and a good fit for them. Many college attainment programs strive to do the same but do not have such high levels of success (Webb et. al, 2017). Research points to the importance of targeted programs which intervene at the right time with the right assistance or incentives to result in large impacts on marginalized students (Carrell \& Sacerdote, 2017).

A few of the elements that are unique to SCA and worth noting include: a strong academic focus on writing, research, critical literacy, and communication skills; incredibly devoted faculty lead by a faculty liaison, committed program staff leaders and college administrators; a strong curriculum and program design built on high expectations; and a large network of extremely satisfied participants and alumnae who are dedicated to the program. Additionally, the commitment of resources to the SCA Program by Scripps College for almost two decades greatly contributes to the program's success. This is supported by the literature that indicates that many of the impactful multifaceted support programs are sponsored and operated by colleges themselves (Page et al., 2019). Finally, findings reveal that through a Ripple Effect or upstream reciprocity, SCA's impact is exponential as the participants are inspired to reach out to support others, in similar ways, through college and throughout their careers. It is the unique combination of these elements that makes SCA a successful program, transforming the lives of hundreds of young women and their current and future families.

\section{SIGNIFICANCE}

Effective program factors and strategies identified in this study and supported in the literature will inform policymakers, researchers, and practitioners in developing and implementing college access and attainment programs that support all students, particularly underrepresented groups. The findings from this

study affirm that participation in special programs for students who are low-income, first-generation, and students of color can ease the transition to college and support students in successfully persisting in college and attaining degrees. Such programs make the college experience attainable by providing college 
knowledge and skills, social-emotional support through personalized attention from staff, and a place to connect with supportive peers who share similar experiences and backgrounds (Engle, \& Tinto, 2008). These results are especially timely and important for institutions serving large numbers of underserved students, given the challenges of a pandemic environment, as they create their own initiatives for college attainment and success.

\section{REFERENCES}

Amaro-Jimenez, C., \& Hungerford-Kresser, H. (2013). Implementing an additive, college access and readiness program for Latina/o high school students in the U.S. Current Issues in Education, 16(3). Retrieved from https://eric.ed.gov/?id=EJ1016231

Apple, M.W. (2012). Knowledge, power, and education: The selected works of Michael W. Apple. Routledge.

Ash, A.N., \& Schreiner, L.A. (2016). Pathways to success for students of color in Christian colleges: The role of institutional integrity and sense of community. Christian Higher Education, 15(1), 38-61. https://doi.org/10.1080/15363759.2015.1106356

Austin, P.C. (2010). Statistical criteria for selecting the optimal number of untreated subjects matched to each treated subject when using many-to-one matching on the propensity score. American Journal of Epidemiology, 172(9), 1092-1097. https://doi.org/10.1093/aje/kwq224

Bernhardt, P.E. (2013). The Advancement Via Individual Determination (AVID) Program: Providing cultural capital and college access to low-income students. School Community Journal, 23(1), 203-22.

Berumen, J.G., Zerquera, D.D., \& Smith, J.S. (2015). More than access: The role of support services in the transitional experiences of underrepresented students in a statewide access program. Journal of Student Financial Aid, 45(1), 27-44.

Boat, A., Sethi, J., Eisenberg, C., \& Chamberlain, R. (2020). "It was a support network system that made me believe in myself": Understanding youth and young adults' experiences of social capital in six innovative programs. Search Institute.

Burke, P.J., Crozier, G., Read, B., Hall, J., Peat, J., \& Francis, B. (2014). Formation of gender and higher education pedagogies $(\mathrm{GaP})$ final report. Higher Education Academy.

Carrell, S., \& Sacerdote, B. (2017). Why do college-going interventions work? American Economic Journal: Applied Economics, 9(3), 124-151. https://doi.org/10.1257/app.20150530

Castleman, B.L., Page, L.C., \& Schooley, K. (2014). The forgotten summer: Does the offer of college counseling after high school mitigate summer melt among college-intending, low-income high school graduates? Journal of Policy Analysis and Management, 33(2), 320-344.

Causey, J., Ryu, M., \& Shapiro, D. (2020). Yearly success and progress rates. Herndon, VA: National Student Clearinghouse Research Center.

Cohen, G.L., \& Garcia, J. (2014). Educational theory, practice, and policy and the wisdom of social psychology. Policy Insights From the Behavioral and Brain Sciences, 1(1), 13-20.

Corbin, J., \& Strauss, A. (2015). Basics of qualitative Research: Techniques and procedures for developing grounded theory (4th ed.). SAGE.

Creswell, J.W., \& Creswell, J.D. (2018). Research design: Qualitative, quantitative, and mixed methods approaches (5th Ed.). Los Angeles, CA: Sage.

Dymnicki, A., Sambolt, M., \& Kidron, Y. (2013). Improving college and career readiness by incorporating social and emotional learning. American Institutes for Research College and Career Readiness and Success Center. Retrieved from https://www.casel.org/wpcontent/uploads/2016/06/Improving-College-and-Career-Readiness-by Incorporating-Social-andEmotional-Learning_0.pdf

Edwards, C.W. (2019, September). Overcoming Imposter Syndrome and Stereotype Threat: Reconceptualizing the Definition of a Scholar. Taboo: The Journal of Culture and Education, 18(1). DOI 10.31390/taboo.18.1.03 
Engle, J., \& Tinto, V. (2008). Moving beyond access: College success for low-income, first-generation students. The Pell Institute.

European Access Network World Congress on Access to Post-secondary Education: Kuala Selangor. (2015). Retrieved from https://10times.com/access-network

Freire, P. (1970). Pedagogy of the oppressed. Continuum Gandin.

Future Citizens. (n.d.). Pay It Forward Scholarship and Mentoring | Future Citizens Foundation. Retrieved from https://www.fcf-ca.org/pay-it-forward

Giroux, H.A. (1996). Fugitive cultures: Race, violence, and youth. Psychology Press.

Goggin, T., Rankin, S., Geerlings, P., \& Taggar, A. (2016). Catching them before they fall: A Vygotskian approach to transitioning students from high school to university. Higher Education Research \& Development, 35(4), 698-711.

Gonzalez, J.J. (2013). The role of social capital and school structure on Latino access to elite colleges. ProQuest LLC.

Halali, E., Kogut, T., \& Ritov, I. (2016, June 13). Reciprocating (more) specifically to you: The role of benefactor's identifiability on direct and upstream reciprocity. Journal of Behavioral Decision Making, 30(2), 473-483.

Han, C., Farruggia, S.P., \& Moss, T.P. (2017, November). Effects of academic mindsets on college students' achievement and retention. Journal of College Student Development, 58(8), 1119-1134.

Harvill, E.L., Maynard, R.A., Nguyen, H.T.H., Robertson-Kraft, C., \& Tognatta, N. (2012). Effects of college access programs on college readiness and enrollment: A meta-analysis. Society for Research on Educational Effectiveness. Retrieved from https://eric.ed.gov/?id=ED530404

Jury, M., Smeding, A., Stephens, N.M., Nelson, J.E., Aelenei, C., \& Darnon, C. (2017). The experience of low SES students in higher education: Psychological barriers to success and interventions to reduce social class inequality. Journal of Social Issues, 73(1), 23-41.

Kilgore, W., Taylor, S.C., \& Pineda, K. (2020). A national snapshot: How students experience and perceive transferring earned credit. Washington DC: American Council on Education.

Latino, C.A., Stegmann, G., Radunzel, J., Way, J.D., Sanchez, E., \& Casillas, A. (2018). The relationship between social and emotional learning skills and resource use for first-year outcomes of Hispanic first generation college students. ACT Research \& Policy. Retrieved from https://www.act.org/content/dam/act/unsecured/documents/R1688-resource-hispanic-fgcs.pdf

Loni Bordoloi, P. (2015). Review of the book The State of College Access and Completion: Improving College Success for Students from Underrepresented Groups ed. by Laura W. Perna and Anthony P. Jones. The Review of Higher Education, 38(2), 322-324. doi:10.1353/rhe.2015.0007

Martinez, J.A., Sher, K.J., Krull, J.L., \& Wood, P.K. (2009). Blue-collar scholars? Mediators and moderators of university attrition in first-generation college students. Journal of College Student Development, 50(1), 87-103.

McCullogh, M.E., Kimeldorf, M.B., \& Cohen, A.D. (2008, August). An adaptation for altruism? The social causes, social effects, and social evolution of gratitude. Current Directions in Psychological Science, 17(4), 281-285.

Mehl, G., Wyner, J., Barnett, E., Fink, J., \& Jenkins, D. (2020). The dual enrollment playbook: A guide to equitable acceleration for students. Washington, DC: The Aspen Institute.

Morrell, E. (2015). Critical literacy and urban youth: Pedagogies of access, dissent, and liberation. Routledge.

National Student Clearinghouse Research Center. (2019, Summer). Snapshot report: First-year persistence and retention for fall 2017 cohort. Retrieved from https://nscresearchcenter.org/wpcontent/uploads/SnapshotReport35.pdf

Page, L.C., Kehoe, S.S., Castleman, B.L., \& Sahadewo, G.A. (2019, Summer). More than dollars for scholars: The impact of the Dell Scholars Program on college access, persistence, and degree attainment. Journal of Human Resources, 54(3), 683-725.

Parkman, A. (2016). The imposter phenomenon in higher education: Incidence and impact. Journal of Higher Education Theory and Practice, 16(1), 51-60. 
Perna, L.W., \& Jones, A. (Eds.). (2013). The state of college access and completion: Improving college success for students from underrepresented groups. Routledge.

Peteet, B.J., Montgomery, L., \& Weekes, J.C. (2015). Predictors of imposter phenomenon among talented ethnic minority undergraduate students. The Journal of Negro Education, 84(2), 175-186.

Porchea, S.F., Allen, J., Robbins, S., \& Phelps, R.P. (2010). Predictors of long-term enrollment and degree outcomes for community college students: Integrating academic, psychosocial, sociodemographic, and situational factors. The Journal of Higher Education, 81(6), 680-708. doi: 10.1080/00221546.2010.11779077

Ramsey, E., \& Brown, D. (2018). Feeling like a fraud: Helping students renegotiate their academic identities. College \& Undergraduate Libraries, 25(1), 86-90. doi: 10.1080/10691316.2017.1364080

Reid, M.J., \& Moore, J.L. (2008). College readiness and academic preparation for postsecondary education: Oral histories of first-generation urban college students. Urban Education, 43(2), 240 261. doi: $10.1177 / 0042085907312346$

Ross, T., Kena, G., Rathbun, A., KewalRamani, A., Zhang, J., Kristapovich, P., \& Manning, E. (2012). Higher Education: Gaps in Access and Persistence Study (NCES 2012-046). U.S. Department of Education, National Center for Education Statistics. Government Printing Office.

Scott-Clayton, J. (2015). The role of financial aid in promoting college access and success: Research evidence and proposals for reform. Journal of Student Financial Aid, 45(3), 6-22.

Stevenson, J. (2012). Black and minority ethnic student degree retention and attainment. Higher Education Academy. Retrieved from: https://s3.eu-west-

2.amazonaws.com/assets.creode.advancehe-documentmanager/documents/hea/private/bme_summit_final_report_1568036653.pdf

Terenzini, P.T., Springer, L., Yaeger, P.M., Pascarella, E.T., \& Nora, A. (1996). First-generation college students: Characteristics, experiences, and cognitive development. Research in Higher Education, $37(1), 1-22$.

Thomas, L. (2012). Building student engagement and belonging in higher education at a time of change: Final report from What Works? Student Retention and Success Program. Paul Hamlyn Foundation.

Tight, M. (2020). Student retention and engagement in higher education. Journal of Further and Higher Education, 44(5), 689-704.

U.S. Department of Education, National Center for Education Statistics. (2019). Digest of Education Statistics, 2018 (NCES 2020-009). Retrieved from https://nces.ed.gov/programs/digest/d18/ch_3.asp

U.S. Department of Housing and Urban Development. (2020). Los Angeles Almanac, poverty and lower living income level Guidelines: Los Angeles County, 2020 \& 2010. Retrieved June 1, 2021, from http://www.laalmanac.com/social/so24_2020.php

Vespa, J., Medina, L., \& Armstrong, D.M. (2020). Demographic Turning Points for the United States: Population projections for 2020 to 2060, current population reports. U.S. Census Bureau. Demographic Turning Points for the United States: Population Projections for 2020 to 2060.

Webb, O., Wyness, L., \& Cotton, D. (2017). Enhancing access, retention, attainment and progression in higher education: A review of the literature showing demonstrable impact. Higher Education Academy.

Yeager, D.S., \& Walton, D.M. (2011). Social-psychological interventions in education: They're not magic. Review of Educational Research, 81(2), 267-301.

Zargarpour, N., Warren, S.R., \& Chen, M.H. (2020, November). Scripps College Academy evaluation report. [Unpublished manuscript] Capacity to Impact, Inc. 